\title{
Modeling impacts of climate change and grazing effects on plant biomass and soil organic carbon in the Qinghai-Tibetan grasslands
}

\author{
Wenjuan Zhang ${ }^{1,2}$, Feng Zhang ${ }^{3}$, Jiaguo $\mathbf{Q i}^{4}$, and Fujiang Hou ${ }^{1}$ \\ ${ }^{1}$ State Key Laboratory of Grassland Agro-ecosystems, College of Pastoral Agriculture Science and Technology, \\ Lanzhou University, Lanzhou, Gansu, 730020, China \\ ${ }^{2}$ Grassland Management Administration of Qinghai Province, Xining, Qinghai, 810008, China \\ ${ }^{3}$ State Key Laboratory of Grassland Agro-ecosystems, Institute of Arid Agroecology, School of Life Sciences, \\ Lanzhou University, Lanzhou, Gansu, 730000, China \\ ${ }^{4}$ Center for Global Change and Earth Observations, Michigan State University, East Lansing, \\ MI 48823, USA
}

Correspondence to: Fujiang Hou (cyhoufj@lzu.edu.cn)

Received: 28 June 2017 - Discussion started: 14 August 2017

Revised: 30 October 2017 - Accepted: 1 November 2017 - Published: 4 December 2017

\begin{abstract}
The Qinghai Province supports over $40 \%$ of the human population of the Qinghai-Tibetan Plateau (QTP) but occupies about $29 \%$ of its land area, and thus it plays an important role in the plateau. The dominant land cover is grassland, which has been severely degraded over the last decade due to a combination of increased human activities and climate change. Numerous studies indicate that the plateau is sensitive to recent global climate change, but the drivers and consequences of grassland ecosystem change are controversial, especially the effects of climate change and grazing patterns on the grassland biomass and soil organic carbon (SOC) storage in this region. In this study, we used the DeNitrification-DeComposition (DNDC) model and two climate change scenarios (representative concentration pathways: RCP4.5 and RCP8.5) to understand how the grassland biomass and SOC pools might respond to different grazing intensities under future climate change scenarios. More than 1400 grassland biomass sampling points and 46 SOC points were used to validate the simulated results. The simulated above-ground biomass and SOC concentrations were in good agreement with the measured data $\left(R^{2} 0.71\right.$ and 0.73 for above-ground biomass and SOC, respectively). The results showed that climate change may be the major factor that leads to fluctuations in the grassland biomass and SOC, and it explained 26.4 and $47.7 \%$ of biomass and SOC variation, respectively. Meanwhile, the grazing intensity explained 6.4 and $2.3 \%$ variation in biomass and SOC, re-
\end{abstract}

spectively. The project average biomass and SOC between 2015 and 2044 was significantly smaller than past 30 years (1985-2014), and it was $191.17 \mathrm{~g} \mathrm{C} \mathrm{m}^{-2}, 63.44 \mathrm{~g} \mathrm{C} \mathrm{kg}^{-1}$ and $183.62 \mathrm{~g} \mathrm{C} \mathrm{m}^{-2}, 63.37 \mathrm{~g} \mathrm{C} \mathrm{kg}^{-1}$ for biomass and SOC under RCP4.5 and RCP8.5, respectively. The RCP8.5 showed the more negative effect on the biomass and SOC compared with RCP4.5. Grazing intensity had a negative relationship with biomass and positive relationship with SOC. Compared with the baseline, the biomass and SOC changed by 12.56 and $-0.19 \%$ for $G_{0}, 7.23$ and 0.23 for $G_{-50}$, and -5.17 and $1.19 \%$ for $G_{+50}$. In the future, more human activity and management practices should be coupled into the model simulation.

\section{Introduction}

Grassland is one of the most widespread terrestrial ecosystems and accounts for nearly $33 \%$ of the land without ice cover (Ellis and Ramankutty, 2008), where it plays important roles in both the global carbon cycle and terrestrial ecosystem processes (Z. Li et al., 2013). The Qinghai-Tibetan Plateau (QTP) covers an area of approximately 130 million hectares (ha), $44 \%$ of China's total grassland (X. L. Li et al., 2013; Piao et al., 2012). This area plays a vital role for the ecological services of China and Southeast Asian countries (Piao et al., 2012; Wang et al., 2002; Y. Li et al., 2013; Zeng 
et al., 2015; Harris, 2010). Qinghai Province supports over $40 \%$ of the population of the QTP, but it has about $29 \%$ of its total area, and thus it plays an important role in the whole QTP (X. L. Li et al., 2013; Piao et al., 2012). This area is recognized as one of the most ecologically fragile and sensitive areas to global climate change and human disturbance (Piao et al., 2012; Wang et al., 2002; Y. Li et al., 2013; Zeng et al., 2015; Harris, 2010). Moreover, this area is also the largest animal husbandry production region in China, and it also contains the headwaters of the two major rivers in China, i.e., the Yellow River and the Yangtze River, and thus it plays a vital role in ecological conservation in China (Zeng et al., 2015).

In recent decades, due to climate change and increased human disturbances, the high-altitude alpine grassland ecosystems, which are the dominant grassland vegetation type, have been severely degraded (Gao et al., 2010; Miehe et al., 2017; Qiao et al., 2015). The air temperature on the plateau has increased by $0.3^{\circ} \mathrm{C}$ decade $^{-1}$, which is 3 times the global average (Li et al., 2008). Warming could significantly increase the net primary productivity of alpine meadows (Fan et al., 2010; Du et al., 2004; Chen et al., 2013). Other studies have found that warming also speeds up the decomposition rate for litter and manure, and increases soil respiration (Xu et al., 2010; Luo et al., 2010), which could cause significant losses of soil organic carbon (SOC) and affect the alpine grassland ecosystem carbon pool balance (Tan et al., 2010; Pei et al., 2009; Babel et al., 2014; Liu et al., 2017). Although the ecological impact of warming on the QTP alpine grassland ecosystem has not been fully elucidated in previous studies, there is no doubt that warming will greatly accelerate the key processes in the alpine grassland ecosystem carbon cycle (Luo et al., 2010). There are reported that both precipitation amount and the number of precipitation days have increased significantly in the QTP (Li et al., 2010). As precipitation is another crucial climate factor in controlling the carbon cycle of grassland ecosystems, how the higher variability precipitation impacts the SOC and biomass in the QTP needs further investigation (Lehnert et al., 2016; Maussion et al., 2014).

Grazing is the most important biotic factor among the ecological processes that affect rapid changes in the vegetation and soil, and it is the main method for deriving ecosystem services from the QTP grassland (Tanentzap and Coomes, 2012). Moreover, grazing is one of the major human disturbances to the grassland in this area. In general, overgrazing is considered to be one of the main causes of carbon and nitrogen losses from the soil, thereby contributing to the unsustainable use of grassland (McIntire and Hik, 2005). Therefore, sustaining a reasonable grazing intensity has an indispensable role in maintaining the turnover of soil nutrients and plant community stability (Klein et al., 2007).

Previous studies have shown that different types of vegetation and soil nutrient pools exhibit significantly different responses to variations in the grazing intensity (Lavado et al., 1996; Ingrisch et al., 2015). However, there is still a lack of robust studies to evaluate the combined effect of grazing and climate change, as well as their impact on the QTP grassland ecosystem on a large scale. Due to the unique geographic characteristics and important ecological functions of the QTP grassland ecosystem, it is necessary to evaluate the impacts of human management and climate change to ensure that it continues to provide these ecosystem services.

In this study, using a well-calibrated DeNitrificationDeComposition (DNDC) model based on long-term vegetation observations, we evaluated the response of the grassland ecosystem in Qinghai Province in terms of both climate change and human management by analyzing the grazing intensity. We also analyzed the interactions between grassland vegetation and soil carbon storage with grazing intensity and climate change disturbances on a large scale in long-term impact assessments.

\section{Materials and methods}

\subsection{Study area}

Qinghai Province $\left(89^{\circ} 35^{\prime}-103^{\circ} 04^{\prime} \mathrm{E}, 31^{\circ} 39^{\prime}-39^{\circ} 19^{\prime} \mathrm{N}\right)$ is located in the northeast of the QTP in China (Fig. 1). This region has a typical plateau climate, with a mean annual temperature of $8.6^{\circ} \mathrm{C}$ (from -6 to $9^{\circ} \mathrm{C}$ across the study area) and a mean annual precipitation of $424.7 \mathrm{~mm}(16.7-776.1 \mathrm{~mm}$ across the study area). In general, the climate is cold and dry. The altitude of Qinghai Province ranges between 1650 and $6860 \mathrm{~m}$ a.s.l. (meters above sea level) and $67 \%$ of the land area is in the range of $3000-5000 \mathrm{~m}$ a.s.l. Grassland is the major land cover in the study area where alpine meadow and alpine steppe are the dominant vegetation types, where they account for $60.5 \%$ of the total grassland area.

Grazing is the primary human activity in the study area and livestock production is a key industry in this region. Generally, natural grassland is the major food source for the livestock in the QTP. Compared with 1949, the number of livestock has increased by almost 3 times from $7.49 \times 10^{6}$ (Zhang, 2011) to the peak number of $22.19 \times 10^{6}$ head in 2005 at the study area (QPBS, 2005, 2015).

Since 2004, the Chinese government has implemented a series of ecological protection projects and policies in Qinghai Province, including reducing livestock and prohibiting grazing, building fences to allow natural grassland recovery, as well as providing allowances and awards to local herdsmen families to promote degraded pasture recovery and to balance the livestock rate according to the forage productivity (Zeng et al., 2015). The core objective of these projects and policies is changing the grazing intensity and achieving a balance between the livestock intensity and grassland regenerability in order to construct a sustainable grassland ecosystem. Due to new policies for ecological protection, the livestock numbers have declined in recent years, but they have 


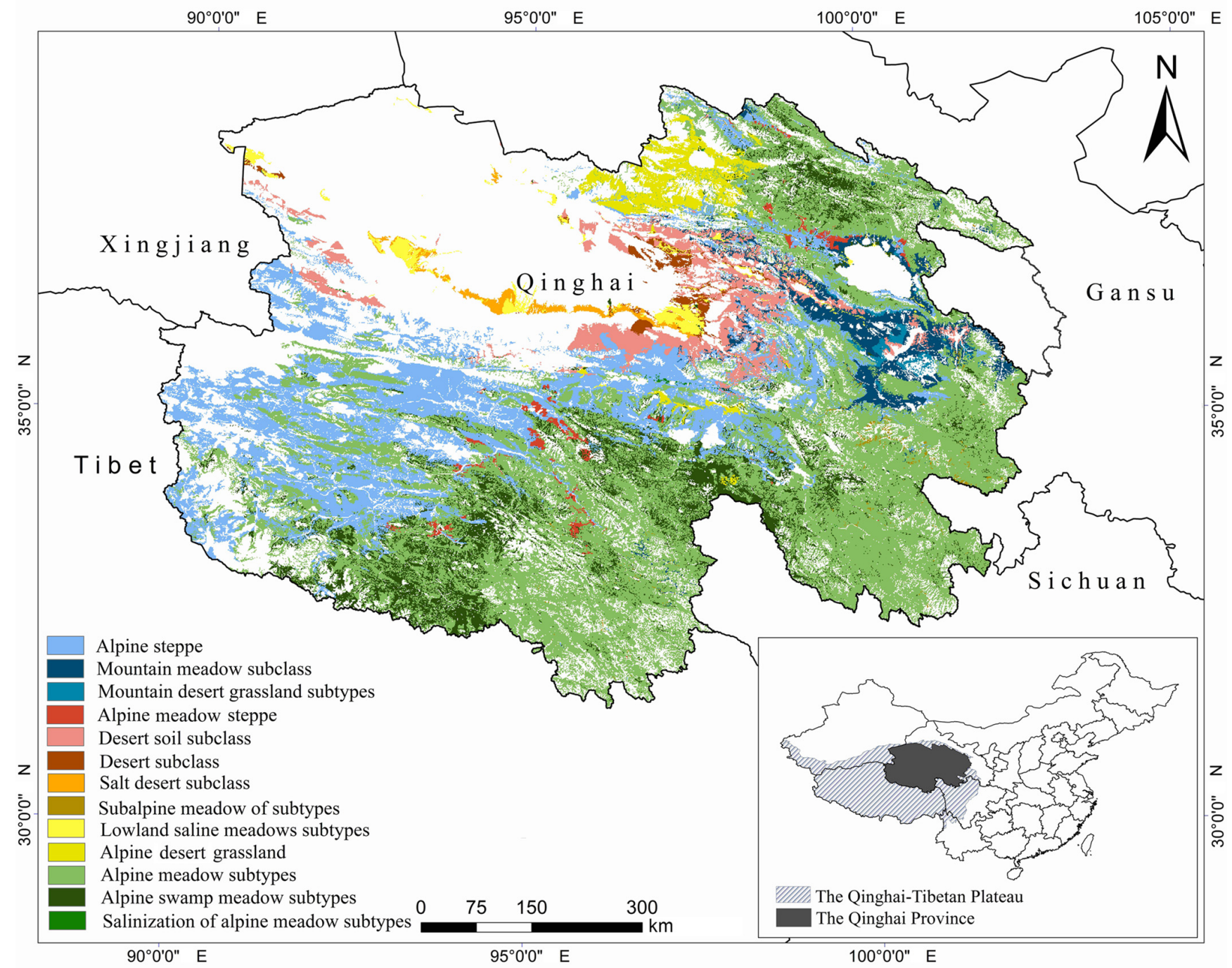

Figure 1. Location of the study area and spatial distribution of the main grassland types. White areas are not covered by grassland.

been maintained at the 2015 level of $19.42 \times 10^{6}$ head (Table S1 in the Supplement) (QPBS, 2015).

\subsection{DNDC model}

The DNDC 9.5 biogeochemical model, which was downloaded from the official web (http://www.dndc.sr.unh.edu/), was employed in this study (Li et al., 1992, 2006). The model has been used widely in more than 20 countries to obtain accurate calibration and verification results in various ecosystems (Abdalla et al., 2009; Chen et al., 2015; Li et al., 1996, 2014, 2017; Xu et al., 2003; Kariyapperuma et al., 2011; Zhao et al., 2016; Liu et al., 2006; Zhang and Niu, 2016).

The model has two components. The first component can simulate the soil environmental conditions, where it includes soil climate, vegetation growth, and decomposition submod- els. The second component includes three submodels for simulating nitrification, denitrification, and fermentation processes, which are used to simulate biogeochemical production, consumption, and emissions of $\mathrm{CH}_{4}, \mathrm{~N}_{2} \mathrm{O}$, NO, and $\mathrm{NH}_{3}$, as well as nitrogen losses due to leaching (Zhang et al., 2015).

The DNDC model simulates vegetation growth by tracking photosynthesis, respiration, water demand, $\mathrm{N}$ demand, $\mathrm{C}$ allocation, crop yield, and litter production. The model predicts the SOC dynamics mainly by quantifying the SOC input from crop litter incorporation and manure amendment, as well as the SOC output through decomposition. More detailed information about the model is given by $\mathrm{Li}$ (1996). 


\subsection{Regional database}

In order to characterize the spatial heterogeneity of natural grasslands in the study area, we collected the following geospatial data as inputs for the DNDC biogeochemical model: grassland type and spatial distribution (Fig. 1), soil properties, and climate data.

\subsubsection{Grassland database}

The vegetation parameters in the model were obtained from a grassland field monitoring project implemented during 2005-2014 (ERSMC-b, 2017; ERSMC-a, 2017). This annual monitoring project covered the major types of grassland within the project area. On average, 168 monitoring sites were sampled each year. For each monitoring site, the average value based on three replicate sampling points was calculated to determine the aboveground biomass value for the monitoring site. The aboveground biomass harvests used the quadrat method during the plant growing season (10 July20 August) in a $1 \mathrm{~m} \times 1 \mathrm{~m}$ plot. A more detailed description of the sampling method used to obtain the observation data can be found in reports by the Ecological Environment Remote Sensing Monitoring Center of Qinghai Province (ERSMC-a, 2017; ERSMC-b, 2017). The grassland simulation based on the grassland functional group type was categorized according to the grassland type map for the study area (Fig. 1). The detailed grassland parameters used in the model were shown in Table S4.

\subsubsection{Soil database}

We used a 1:1000000-scale soil database developed by the Institute of Soil Science, Chinese Academy of Sciences, which was compiled based on the second national soil survey conducted in 1979-1994 for all the counties in China (Shi et al., 2004). The database had three attributes: locations, soil attributes, and reference systems. It contained multi-layer soil properties (e.g., organic matter, $\mathrm{pH}$, and bulk density), soil texture (e.g., sand, silt and clay proportions), and spatial information (Shi et al., 2004; Yu et al., 2007a, b), which were used in the model simulations.

\subsubsection{Climate database}

Daily climate data were obtained from the China Meteorological Network for the study period, and there were 39 stations inside the study areas (http://data.cma.cn/). The daily precipitation and maximum/minimum temperatures between 1985 and 2014 were interpolated at $1 \mathrm{~km}$ resolution grid for our model. Regression kriging and the inverse distance method were employed for air temperature and precipitation interpolation, respectively (Fortin and Dale, 2005; Hengl et al., 2007).

\subsubsection{Model implementation}

All datasets were processed with ArcGIS version 10.2 (ESRI, Redlands, CA) to form a georeferenced DNDC regional simulation database. The data processing flowchart can be found in Fig. S1 in the Supplement. The county boundary data were overlaid on grassland type maps to form the model simulation unit. Then county-based grazing intensity, soil properties, and climate information were assigned to the model simulation units. The DNDC was run with a regional simulation database based on individual model simulation units. Detailed information of how to run the model can be found in Li (2012). The actual climate, soil, grassland type and grazing intensity as the simulation baseline.

\subsection{Simulation scenarios}

\subsubsection{Grazing simulation scenarios}

The grazing period is all year round and cattle (90\% yaks), sheep, and goats are major livestock types, while horses are a minor component in the study area. The grazing intensity data were based on the annual national livestock statistical report provided by the National Bureau of Statistics of China and the Bureau of Statistics for Qinghai Province. The detailed grazing data are shown in Table S3. In the DNDC model, grazing activity is defined by specifying the grazing parameters, including the livestock type, grazing period, and grazing intensity. The detailed parameters for simulating grass growth are shown in Table S4. The grazing intensity is defined according to Eq. (1) based on the grazing area in each administrative region ( $\mathrm{Li}$ et al., 2014):

$\mathrm{GI}=\mathrm{LP} / \mathrm{GA}$,

where GI is the grazing intensity (head ha ${ }^{-1}$ ), LP is the livestock unit (head), and GA is the grazing area (ha).

In order to test the responses of the grassland biomass and soil SOC to various grazing intensities, we tested the following treatments: baseline, grazing intensity based on the actual grazing intensity in 2005; $G_{0}$, grazing intensity of zero; $G_{-50}, 50 \%$ of the baseline intensity; and $G_{+50}, 50 \%$ higher than the baseline.

\subsubsection{Climate change scenarios}

The Intergovernmental Panel on Climate Change (IPCC) Fifth Assessment Report employed new stable concentration-based scenarios in representative concentration pathways (RCPs) to project future climate change (IPCC, 2013). The development of the RCP scenarios used a parallel method, which combined climate, air, and the carbon cycle with emissions and the socio-economic situation to assess the impact of climate change on a study area, as well as adaptation, vulnerability, and mitigation analysis (Moss et al., 2010). The RCPs were named according to 
Table 1. Projected climatic changes (precipitation and maximum, minimum, and mean air temperature) under the RCP4.5 and RCP8.5 scenarios in 2044 compared with the corresponding values in the baseline data (2014).

\begin{tabular}{lrrrr}
\hline \multirow{2}{*}{ Scenarios } & \multicolumn{3}{c}{ Air temperature $\left({ }^{\circ} \mathrm{C}\right)$} & Precipitation \\
\cline { 2 - 4 } & $T_{\max }$ & $T_{\min }$ & $T_{\text {mean }}$ & $(\mathrm{mm})$ \\
\hline Baseline & 3.63 & -16.88 & -3.56 & 279.24 \\
RCP4.5 & +0.99 & +0.44 & +0.72 & +11.81 \\
RCP8.5 & +1.09 & +0.51 & +0.80 & +12.50 \\
\hline
\end{tabular}

their 2100 radiative forcing level and reported by individual modeling teams, i.e., $2.6-8.5 \mathrm{~W} \mathrm{~m}^{-2}$. The RCPs comprise four scenarios, i.e., RCP2.6, RCP4.5, RCP6.0, and RCP8.5 (Moss et al., 2010). Each scenario provides a path affected by social and economic conditions and climate, and each projection corresponds to the radiation force value predicted by 2100 .

We considered RCP4.5 and RCP8.5 because these two scenarios have been used widely to evaluate the potential impact of climate change on the environment (Di Vittorio et al., 2014; Zhang et al., 2013; Li et al., 2015; van Vuuren et al., 2011). RCP4.5 represents a medium-low RCP with stabilization of $\mathrm{CO}_{2}$ emissions from 2150 onwards, and RCP8.5 represents a high RCP with stabilizing $\mathrm{CO}_{2}$ emissions post-2100 (Meinshausen et al., 2011). The projected climate conditions in the present study under RCP4.5 and RCP8.5 were derived from the average values of 25 Coupled Model Intercomparison Project Phase 5 (CMIP5) global climate models (Fu and Feng, 2014).

Compared with 2014, the average temperature and precipitation increased by 0.72 and $0.80^{\circ} \mathrm{C}$ and by 11.81 and $12.50 \mathrm{~mm}$ under RCP4.5 and RCP8.5 in 2044, respectively, in the study area (Table 1). The changes in the spatial distribution of precipitation are shown in Fig. S2. The pattern of increased precipitation was similar using RCP4.5 and RCP8.5 for the period of 2014-2044, where it increased in the whole area as well as gradually from the north to the south of the study area. However, RCP8.5 obtained a higher increase than RCP4.5, and the southwestern part of the research area is projected to have a higher temperature increase than the other regions. Moreover, the annual average temperature had a similar distribution under the two climate change scenarios, where the temperature increase using RCP4.5 (Fig. S2c) was lower than that with RCP8.5 (Fig. S2d).

Three different periods were considered in the grassland simulations. First, a pretreatment (1961-1984) period was used to initialize the soil climate conditions and SOC composition. The pretreatment period represented the baseline climate with no increases in $\mathrm{CO}_{2}$ or climate change. The second period represented realistic climate scenarios (1985-2014) based on the most recent climate. The third period comprised future climate scenarios (2015-2044), which represented two future climates (RCP4.5, RCP8.5) scenarios with changes in temperature and precipitation. The future climate database between 2015 and 2044 was obtained through adding the projected future climate change to the daily temperature and precipitation in 2014.

\subsection{Model validation and sensitivity test}

The root mean squared error (RMSE) (Eq. 2), coefficient of determination $\left(R^{2}\right)$ (Eq. 3) and model efficiency (ME) (Eq. 4) were employed for model validation. The RMSE estimates the scatter between the simulated and measured data, where values close to zero indicate excellent agreement and hence the good performance of the model (Araya et al., 2015). $R^{2}$ is used to test the agreement between the modeled results and observations, where a value closer to 1 indicates that the model provides a better explanation for the observed values (Willmott, 1982). The positive ME value indicates that the model prediction is better than the mean of observations, and the best model performance has ME value equal to 1 (Miehle, 2006). RMSE, $R^{2}$ and ME were calculated as follows:

$$
\begin{aligned}
& \text { RMSE }=\sqrt{\frac{\sum_{i=1}^{n}\left(P_{i}-O_{i}\right)^{2}}{n},} \\
& R^{2}= \\
& \quad\left[\frac{\sum_{i=1}^{n}\left(O_{i}-\bar{O}\right)\left(P_{i}-\bar{P}\right)}{\sqrt{\sum_{i=1}^{n}\left(O_{i}-\bar{O}\right)^{2}}} \sqrt{\sum_{i=1}^{n}\left(P_{i}-\bar{P}\right)^{2}}\right]^{2}, \\
& \mathrm{ME}=1-\frac{\sum_{i=1}^{n}\left(P_{i}-O_{i}\right)^{2}}{\sum_{i=1}^{n}\left(O_{i}-\bar{O}\right)^{2}},
\end{aligned}
$$

where $P_{i}$ and $O_{i}$ are modeled and observed values, and $\bar{P}$ and $\bar{O}$ are their averages. $n$ is the number of values.

The validation dataset included more than 1400 grassland biomass sampling points, which covered the whole of the study area, and the field measurements were also fully representative of the major grassland types in this area. In addition, 46 SOC observation points were sampled between 2011 and 2012, which were randomly distributed among all of the simulation units (county and grassland types). Maximum biomass in each quadrat was harvested and dried in an oven at $70^{\circ} \mathrm{C}$ for $72 \mathrm{~h}$, weighed and ground for analysis. The soil of $0-30 \mathrm{~cm}$ depth was sampled at $10 \mathrm{~cm}$ intervals with a soil drill (metal cylinder with diameter $5 \mathrm{~cm}$, length $20 \mathrm{~cm}$ and total length $1.3 \mathrm{~m}$ ). Three samples were collected in each replication plot. The ground soil samples passed a $0.15 \mathrm{~mm}$ sieve and wet oxidation method was applied to determine SOC (Mebius, 1960). In general, every simulation unit had 1-2 validation points (ERSMC-a, 2017).

A series of sensitivity tests were conducted to investigate the responses of the DNDC to variation in climate factors (air temperature, precipitation) and grazing intensity. DNDC 


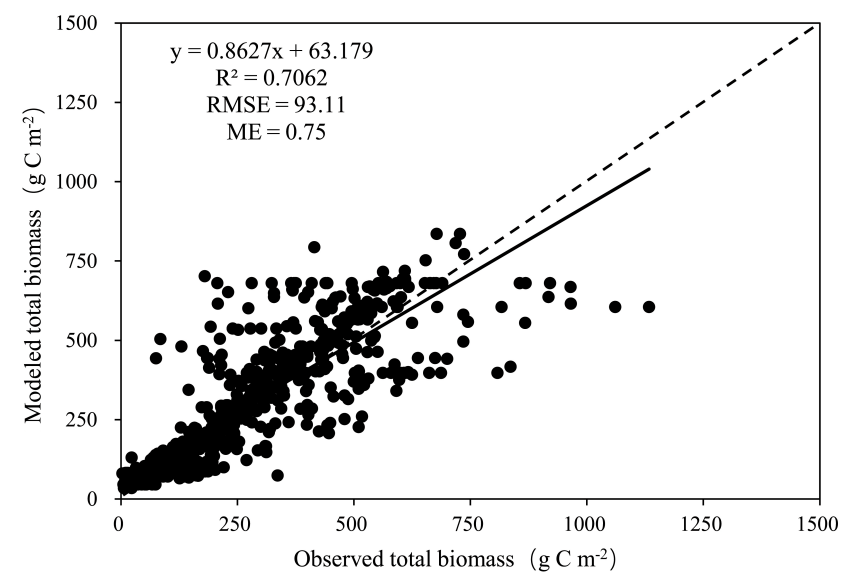

Figure 2. Comparison of the modeled and observed total biomass values.

was run with a 55-year baseline scenario that was based on the actual climate, soil and grazing conditions of year 2005 in the study area. The ranges of values for alternative scenarios were $\pm 10, \pm 20$ and $\pm 30 \%$ for precipitation, $\pm 1, \pm 2$ and $\pm 3{ }^{\circ} \mathrm{C}$ for air temperature and $\pm 20, \pm 40, \pm 60, \pm 80$ and $\pm 100 \%$ for grazing intensity, respectively.

\subsection{Statistical analysis}

Two-way analysis of variance (ANOVA) was used to test the effects of climate and grazing intensity on both the biomass and SOC according to the simulated results. Mean values for the same treatments were compared using Fisher's least significant difference (LSD) test with one-way ANOVA at $P=0.05$. The statistical analyses, including the test for normality (Shapiro-Wilk) and homogeneity of variance (Levene), were performed using Origin 2016 version b9.3.1.273 (OriginLab Corporation, MA, USA), and the multiple regression analysis was conducted with the Minitab version 17 (Minitab Inc., State College, PA, USA).

\section{Results}

\subsection{Model validation}

The biomass simulation showed that the modeled total biomass was in good agreement with the observations (Fig. 2). There was a significant linear relationship $(P<0.001)$ between the measurements and the modeled above-ground biomass $\left(R^{2}=0.71, \mathrm{ME}=0.75\right.$, RMSE $\left.=93.11 \mathrm{~g} \mathrm{C} \mathrm{m}^{-2} ; \quad P<0.001\right)$. The simulated SOC concentrations were in good agreement with the measured data (Fig. 3). The calculated statistical indices indicated that the modeled SOC concentrations were closely correlated with the measured data $\left(R^{2}=0.73, \mathrm{ME}=0.69\right.$, $\left.\mathrm{RMSE}=21.51 \mathrm{~g} \mathrm{C} \mathrm{kg}^{-1} ; P<0.001\right)$.

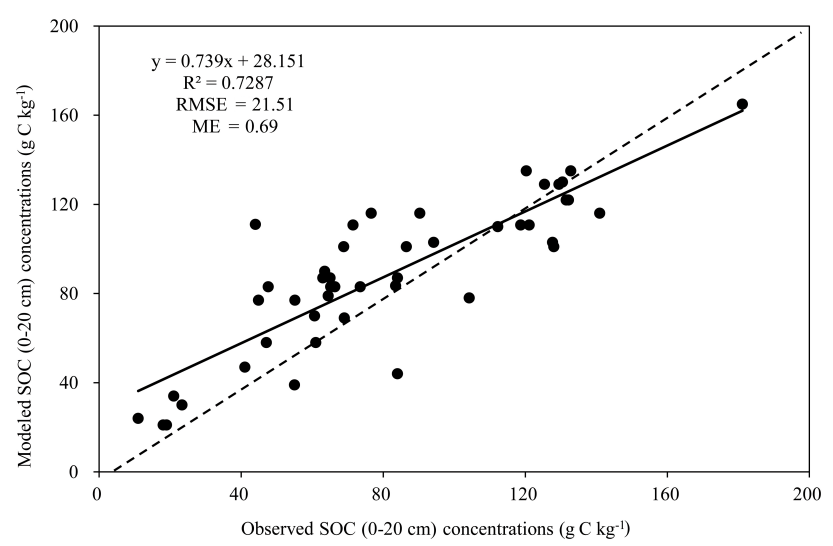

Figure 3. Comparison of the modeled and observed SOC concentrations $(0-20 \mathrm{~cm})$.

\subsection{Sensitivity analysis}

In the sensitivity analysis simulation, increases in precipitation resulted in elevated biomass and SOC. However, the SOC was changed slightly compared to the biomass (Fig. 4a, b); temperature decrease induced the biomass decrease, and temperature increase could increase the biomass. However, biomass change did not follow a simple linear relationship with change in temperature. The $1{ }^{\circ} \mathrm{C}$ temperature increase could bring $24 \%$ of biomass increase; at the same time, a $1{ }^{\circ} \mathrm{C}$ temperature decrease could decrease $13 \%$ biomass (Fig. 4a). Biomass was not susceptible to the changes in precipitation. The biomass increased $7 \%$ and decreased $6 \%$ with precipitation increased and decreased $30 \%$, respectively. SOC had the reverse trend with increased or decreased temperature, but there was a more complex relationship with temperature change. The SOC had less sensitivity to temperature change compared to biomass. With a $1{ }^{\circ} \mathrm{C}$ temperature increase, the SOC increased slightly by $0.26 \%$, but when temperature increased over $2^{\circ} \mathrm{C}$, the SOC decreased by $0.26-0.83 \%$ (Fig. $4 \mathrm{~b}$ ). The modeled biomass was sensitive to grazing intensity and biomass had a reverse trend with increased or decreased grazing intensity (Fig. 4a). When grazing intensity changed from -100 to $100 \%$, SOC increased rate from -0.22 to $0.40 \%$ (Fig. 4 b).

\subsection{Impact of grazing on biomass and SOC}

The biomass and SOC were significantly affected by climate change and the grazing intensity. However, there were no significant interaction effects between climate and grazing intensity on biomass and SOC during 1985-2044 throughout the study area (Table 2). The grazing intensity change could significantly influence the biomass, which had a negative relationship with the grazing intensity. The biomass differed significantly under the four grazing intensities. Among the grazing intensity treatments, the biomass followed the 

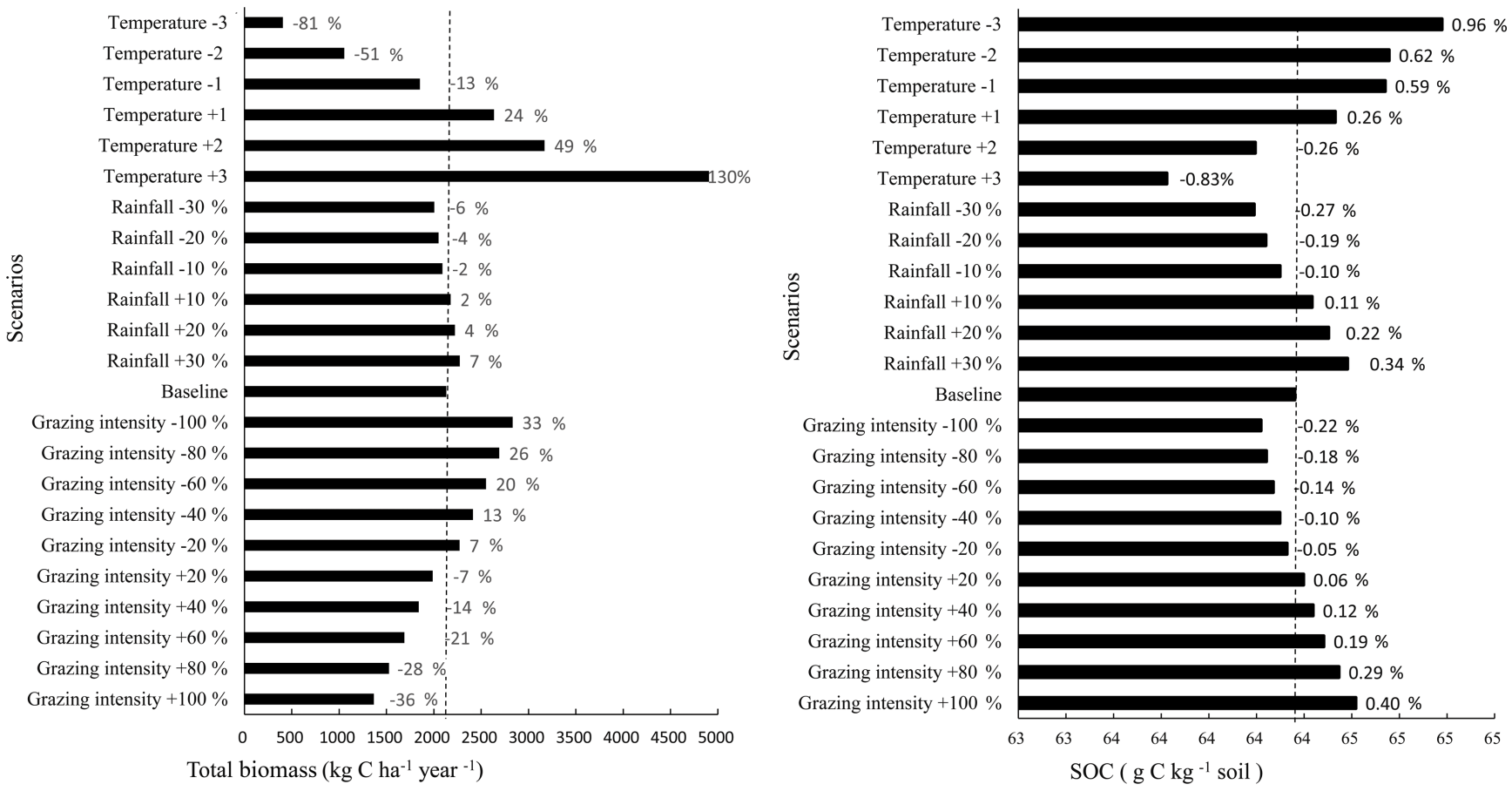

Figure 4. Sensitivity analysis of model response to climate and grazing intensity change. The baseline biomass and SOC were the average value of a 55-year (1961-2014) simulation based on the actual climate and grazing conditions in the study area.

Table 2. Summary of two-way analysis of variance for biomass and SOC relative to the climate, grazing intensity, and their interactions during 1985-2044. Degrees of freedom (d.f.), mean squares (M.S.), variance ratio ( $F$ value), and level of significance $(P$ value) are shown.

\begin{tabular}{lrrrr|rrr}
\hline Source of variation & d.f. & \multicolumn{3}{c}{ Biomass } & \multicolumn{3}{c}{ SOC } \\
\cline { 3 - 8 } & & M.S. & $F$ value & $P$ value & M.S. & $F$ value & $P$ value \\
\hline Climate & 2 & 16827.91 & 54.27 & $*$ & 468.16 & 723.54 & $*$ \\
Grazing intensity & 3 & 22132.64 & 71.37 & $*$ & 17.29 & 26.72 & $*$ \\
Climate $\times$ grazing intensity & 6 & 2.63 & 0.01 & n.s. & 0.28 & 0.28 & n.s. \\
\hline
\end{tabular}

* Population means of the treatment are significantly different at 0.05 level; "n.s." indicates no significant difference.

order of $G_{0}>G_{-50}>$ baseline $>G_{+50}$ (Table 3). Compared with the baseline, the biomass changed by $12.56,7.23$ and $-5.17 \%$ for the treatment $G_{0}, G_{-50}$ and $G_{+50}$, respectively. Grazing could increase the SOC storage. The SOC levels under various grazing intensities followed the order of: $G_{0}<G_{-50}<$ baseline $<G_{+50}$ (Table 3). $G_{0}$ had the lowest SOC, whereas $G_{+50}$ had the highest SOC. Compared with the baseline, the SOC changed by $-0.19,0.23$ and $1.19 \%$ for the treatment $G_{0}, G_{-50}$ and $G_{+50}$, respectively.

\subsection{Impact of climate change on biomass and SOC}

The biomass exhibited a significant decreasing trend in the future climate scenarios compared with the past 30 years under all the grazing intensities (Fig. 5), although precipitation increased under both RCP4.5 and RCP8.5 (Table 1). Moreover, the biomass was significantly lower in RCP8.5 com- pared with RCP4.5 (Table 3). Compared with 1985-2014, the simulated biomass decreased by -6.29 and $-9.99 \%$ in 2015-2044 under RCP4.5 and RCP8.5, respectively. This suggests that RCP8.5 had a more negative effect on the biomass compared with RCP4.5 (Fig. 5). The future climate could significantly decrease the SOC, and it was -4.14 and $-4.25 \%$ lower than that in 2015-2044 for RCP4.5 and RCP8.5, respectively. This suggests that RCP8.5 had a more negative effect than the RCP4.5 on the SOC. SOC exhibited a continuously decreasing trend according to the RCP4.5 and RCP8.5 projections in the research area, where the changes in the SOC were similar under the different grazing treatments (Fig. 6). The SOC was lower under RCP8.5 compared with that under RCP4.5. However, there were no significant differences between RCP4.5 and RCP8.5 (Table 3). 
Table 3. The simulated SOC concentrations and total biomass under climate and grazing scenarios.

\begin{tabular}{llrr}
\hline Scenarios & $\begin{array}{r}\text { Total biomass } \\
\left(\mathrm{g} \mathrm{C} \mathrm{m}^{-2}\right)\end{array}$ & $\begin{array}{r}\text { SOC }(0-20 \mathrm{~cm}) \\
\begin{array}{r}\text { concentrations } \\
\left(\mathrm{g} \mathrm{C} \mathrm{kg}^{-1}\right)\end{array}\end{array}$ \\
\hline Climate & Realistic (1985-2014) & 204.01 & 66.18 \\
& RCP4.5 (2015-2044) & 191.17 & 63.44 \\
& RCP8.5 (2015-2044) & 183.62 & 63.37 \\
& LSD $_{0.05}$ & 3.87 & 0.09 \\
\hline Grazing & Baseline & 187.83 & 64.49 \\
& $G_{0}$ & 211.42 & 64.37 \\
& $G_{-50}$ & 201.41 & 64.64 \\
& $G_{+50}$ & 178.11 & 65.26 \\
& LSD $_{0.05}$ & 4.47 & 0.10 \\
\hline
\end{tabular}

$\mathrm{LSD}_{0.05}$ : least significant difference at 0.05 level.



Figure 5. Variations in the area-weighted mean biomass value under different scenarios. Section (a) represents the preprocessing period from 1961 to 1984. Section (b) represents the realistic climate scenarios. Section (c) represents future climate scenarios.

\subsection{The relationship between SOC and biomass change with grazing and climate factors}

A multiple linear regression analysis was adopted for each simulation unit to analyze the relationship between the annual changed biomass and SOC with corresponding temperature, precipitation and grazing intensity. The regression analysis indicated precipitation, air temperature and combined with grazing intensity, can explain $33.2 \%$ of changes in biomass under the realistic climate scenarios with a linear model. Meanwhile, precipitation, air temperature, and grazing intensity can explain $52.3 \%$ of SOC variation (Table 4). Specifically, climate factors explained 26.4 and
$47.7 \%$ of biomass and SOC variation, respectively. Meanwhile, the grazing intensity explained 6.4 and $2.3 \%$ variation in biomass and SOC, respectively. Taking into account the prediction sum of squares (PRESS) value, air temperature is the factor contributing most of variations in biomass and SOC. It is suggested that precipitation and grazing intensity have lower contributions to biomass and SOC change in the study region during the past 30 years compared to temperature. 


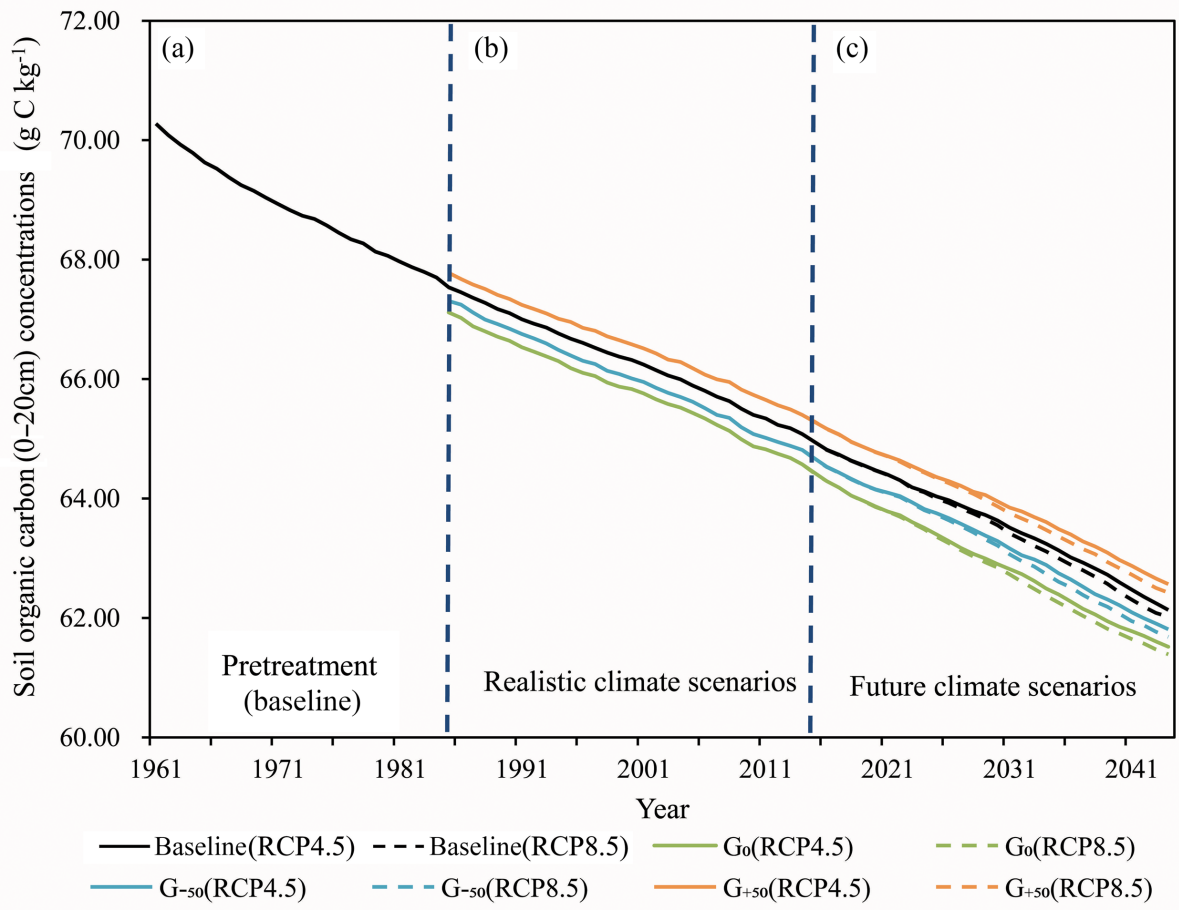

Figure 6. Variations in the area-weighted mean SOC value under different scenarios. Section (a) represents the preprocessing period from 1961 to 1984 . Section (b) represents the realistic climate scenarios. Section (c) represents future climate scenarios.

Table 4. Multiple linear regression analysis of grassland biomass and SOC change with relative factors.

\begin{tabular}{|c|c|c|c|c|c|c|}
\hline & $\begin{array}{c}\text { Variables } \\
\text { numbers }\end{array}$ & $R^{2}$ & PRESS & Temperature & Precipitation & $\begin{array}{l}\text { Grazing } \\
\text { intensity }\end{array}$ \\
\hline \multirow[t]{7}{*}{ Biomass } & 1 & 26.4 & 273067.7 & $X$ & & \\
\hline & 1 & 6.4 & 370402.4 & & & $X$ \\
\hline & 1 & 0.4 & 349337.6 & & $X$ & \\
\hline & 2 & 26.4 & 287817.3 & $X$ & $X$ & \\
\hline & 2 & 26.4 & 301908.4 & $X$ & & $X$ \\
\hline & 2 & 8.6 & 383224.5 & & $X$ & $X$ \\
\hline & 3 & 26.4 & 326183.5 & $X$ & $X$ & $X$ \\
\hline \multirow[t]{7}{*}{ SOC } & 1 & 47.6 & 179.2 & & $X$ & \\
\hline & 1 & 2.3 & 310.9 & & & $X$ \\
\hline & 1 & 0.4 & 322.9 & $X$ & & \\
\hline & 2 & 47.9 & 185.5 & & $X$ & $X$ \\
\hline & 2 & 47.7 & 189.5 & $X$ & $X$ & \\
\hline & 2 & 4.7 & 328.8 & $X$ & & $X$ \\
\hline & 3 & 48.6 & 199.1 & $X$ & $X$ & $\mathrm{X}$ \\
\hline
\end{tabular}

PRESS: the prediction residual sum of squares. The smaller the PRESS value, the better the model's predictive ability. "X" indicates variable applied in the regression.

\subsection{Patterns of regional change in the biomass and SOC}

From a spatiotemporal distribution perspective, the distribution of grassland biomass in Qinghai Province is rather distinct due to the different constraints imposed by water and the cumulative temperature. The biomass increased in the cen- tral and southwest of the research region but decreased in the eastern and northern regions under RCP4.5 and RCP8.5, respectively. Moreover, the grassland biomass tended to decrease in more regions rather than exhibiting an increasing trend (Fig. 7a). In particular, the vegetation activities are mainly controlled by temperature in the eastern region, which may lead to greater negative effects than the positive 

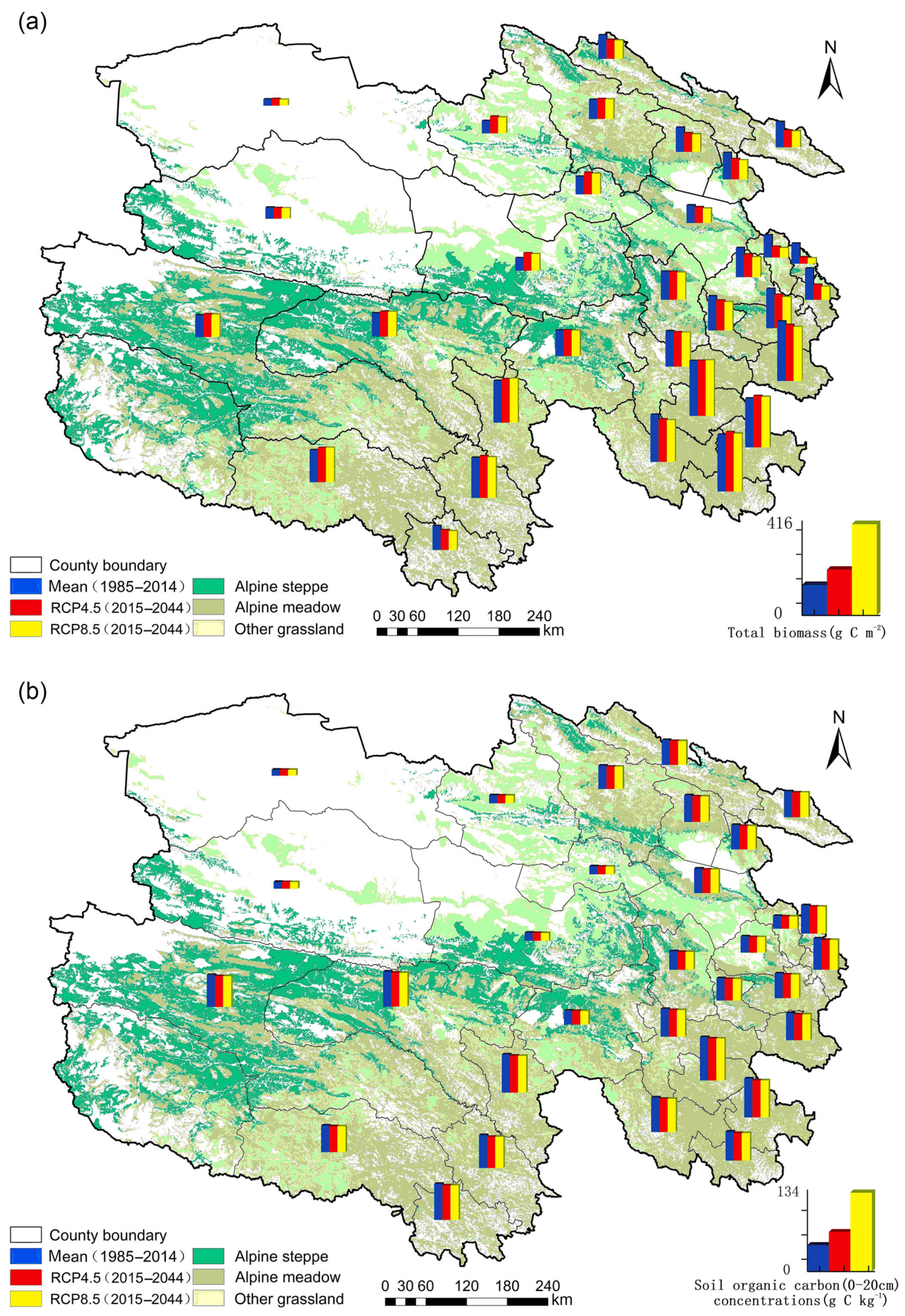

Figure 7. Responses of the grassland biomass (a) and SOC (b) to climate change at a regional scale.

effects of increased precipitation (Zhou et al., 2007); therefore, the average regional biomass may exhibit a significant decreasing trend.

In general, the SOC decreased from the low-temperature region to the high-temperature region, where it followed the temperature distribution pattern in Qinghai Province and decreased from the south to the north (Fig. 7b). The cold weather conditions would limit decomposition process and there would be greater carbon storage over the years with accumulation in this area. Furthermore, on the regional scale, although the SOC exhibited a decreasing trend in the whole 
study area, the rate of change differed with a significant spatial distribution pattern.

\section{Discussion}

\subsection{Effects of climate change on biomass and SOC}

Climate change is the main driver of the interannual fluctuations in the grassland biomass, as observed in previous studies by Fan et al. (2010) and Gao et al. (2016). The unique climate conditions such as precipitation and temperature on the QTP have a significant impact on the grassland biomass (Fan et al., 2010; Yan et al., 2015). According to this study, the biomass of alpine grassland could increase significantly in the short term as the temperature increases (Fig. 4), as also suggested by Chen et al. (2013) and Gao et al. (2016). However, under long-term constant warming and without considering other meteorological factors, the alpine grassland biomass will probably decrease (Zhu et al., 2016). This may be due to the higher temperature increasing evaporation in the study area, thereby overcoming the benefits of increased precipitation (Xu et al., 2009). The shortage of water will ultimately limit the increase in the grassland biomass with significant warming and drying.

The decline of the SOC in our study indicates that climate warming will have more negative effects and eliminated the positive effect of precipitation increasing in the study area. Riedo et al. (2000) indicated that carbon storage may be lost from grazed grassland as the temperature and precipitation increase. Tan et al. (2010) suggested that after a $2{ }^{\circ} \mathrm{C}$ increase in temperature in the QTP, the grassland ecosystem's net primary productivity will increase by $9 \%$, but the SOC will decrease by $10 \%$. Temperature and precipitation are the main factors that affect the SOC pools (Jobbagy and Jackson, 2000). Many studies have shown that sustained warming will lead to increases in the SOC decomposition rate (Xu et al., 2012; Tan et al., 2010), especially in the QTP region, with high carbon storage at a low temperature in the high latitudes. Thus, the SOC could be released by climate warming and become a more obvious carbon source (Kirschbaum, 1995; Kvenvolden, 1993; Yang et al., 2008; Wang et al., 2008; Qin et al., 2014). However, the effects of warming and precipitation on SOC storage remain a relatively complex problem (Cao and Woodward, 1998; Schuur, 2003).

\subsection{Effects of grazing intensity on biomass and SOC}

The grazing intensity is most important for the outcomes of grazing and it is the main external factor that controls the grassland vegetation dynamics, as reported in previous studies (Zeng et al., 2015; Veen et al., 2012; Guevara et al., 1996; McIntire and Hik, 2005; Pei et al., 2008). Indeed, an increase in the grazing intensity implies that more plants would be removed by animals, which could eventually lead to a de- cline in the aboveground biomass of the grassland (Yan et al., 2013).

Small differences in the SOC concentrations were observed after the grazing intensity increased. However, there was a positive correlation between the grazing intensity and SOC. There is a lack of consistent conclusions regarding the impact of grazing on the SOC concentration according to previous studies. Thus, some studies showed that the grazing intensity and SOC had a negative correlation (Derner et al., 1997; Bagchi and Ritchie, 2010; Wu et al., 2009) or no relationship (Milchunas and Lauenroth, 1993; Holt, 1997). By contrast, many other studies showed that grazing can increase the SOC (Schuman et al., 1999; Wienhold et al., 2001; Li et al., 2011). This is partly because moderate grazing can increase the grassland belowground biomass, which is beneficial for the accumulation of SOC (López-Mársico et al., 2015; Hafner et al., 2012). Some studies have shown that increasing the plant root/ shoot ratio and allocating more carbon to the root system could induce SOC increase (Derner et al., 1997). Nevertheless, the main reason for the increase in the SOC in our study was the increasing number of grazing animals and thus the increased amount of manure returned after grazing on grassland (Hu et al., 2016). Furthermore, the fertilizing effects of livestock excrement can increase the SOC (Conant et al., 2001), especially in alpine grassland, where the low temperature leads to the relatively slow decomposition of litter (Davidson and Janssens, 2006). Moreover, increases in the effects of hoof activity can accelerate the decomposition of litter and decaying roots and improve the contact with the soil, thereby accelerating the transfer of carbon to the soil to increase the SOC concentration (Naeth et al., 1991; Luo et al., 2010).

\subsection{Uncertainty analysis}

Models are ideal tools for assessing the details of environment processes under various grazing intensity. Furthermore, they can provide projections regarding the variations in grassland biomass and SOC under alternative climate change scenarios. However, the uncertainty of the data sources could be incorporated into the model outputs. The CMIP5 RCP scenarios were used to provide the possible changes in climate in this study, but as a long-term climate projection, the uncertainty in the projected climate will increase as the time span increases (Moss et al., 2010). The precipitation seasonal distribution pattern is critical to grassland growth (Shen et al., 2011). In the present study, the precipitation distribution pattern of RCP scenarios was derived from the year of 2014; this assumption may cause uncertainty for long-term study.

In the present study, we assumed that the grassland type was the same in the scenarios. As the grassland community structure could be altered under both grazing and climate change (Koerner and Collins, 2014). Therefore, the assumption that grassland community structure remains stable in the simulation could induce the uncertainty. Due to a lack 
of mechanisms regarding the response of grassland soil to animal trampling in the DNDC model, we ignored the trampling effect of the animals on the soil structure, which may have led to some errors in the results.

The grazing rate can be another potential source of uncertainty. In most of the natural grassland regions of the QTP, transhumance is usually practiced, which requires the transfer of livestock from one pasture to another during different seasons and staying in the same pasture for the whole season. However, this grassland management practice was simplified in the present study because we could not find specific statistical data to address this issue. Thus, we assumed that livestock stayed in the same pasture for the whole year with $24 \mathrm{~h} \mathrm{~d}^{-1}$ of grazing and the stocking rates were the same throughout the simulation unit and without yak dung removal (Zhang et al., 2016). Furthermore, we assumed that all grasslands were useable. These assumptions could have induced uncertainties in the simulation results.

\section{Conclusions}

In this study, we used the DNDC model to study the grassland biomass and SOC dynamics under different climate change and grazing management scenarios. We found that climate change may be the major factor that leads to fluctuations in the grassland biomass and SOC compare to grazing intensity, and it could explain 26.4 and $47.7 \%$ of biomass and SOC variation, respectively. Meanwhile, the grazing intensity explained 6.4 and $2.3 \%$ variation in biomass and SOC, respectively. The total grassland biomass and average SOC in the study area were reduced significantly under both the RCP4.5 and RCP8.5 future climate change scenarios. Compared with 1985-2014, the simulated biomass and SOC decreased by -6.29 and $-4.14 \%$ and -9.99 and $-4.25 \%$ under RCP4.5 and RCP8.5, respectively. There were significant differences in the spatial distribution of the changing trends in the biomass and SOC. In the eastern and northern regions of the study area, the biomass decreased, whereas it exhibited an increasing trend in the southwest part of the research area. Meanwhile, the SOC exhibited a decreasing trend in the whole study area, and SOC change rate decreased from the south to the north. The biomass had a negative relationship with the grazing intensity and it differed significantly under the four grazing intensities. Compared with the baseline, the biomass changed by $12.56,7.23$ and $-5.17 \%$ for the treatment $G_{0}, G_{-50}$ and $G_{+50}$, respectively. Grazing could increase the SOC storage. $G_{0}$ had the lowest SOC, whereas $G_{+50}$ had the highest SOC. Compared with the baseline, the SOC changed by $-0.19,0.23$ and $1.19 \%$ for the treatment $G_{0}, G_{-50}$ and $G_{+50}$, respectively. Overall, grassland management should be adapted to potential climate change to ensure sustainable grassland development in the study area.
Data availability. The DNDC model version 9.5 used in this study is a free software and can be downloaded from http://www.dndc.sr. unh.edu/model/DNDC95.rar (last access: 30 November 2017). The model source code is distributed under the Software License Agreement of the Institute for the Study of Earth, and it can be accessed on personal request to Jia Deng at jia.deng@unh.edu, Earth Systems Research Center, Institute for the Study of Earth, Oceans and Space, University of New Hampshire, Durham, New Hampshire, USA. The climate database (Dataset Of Daily Climate Data From Chinese Surface Stations For Global Exchange (V3.0)) can be downloaded from the Climatic Data Center, National Meteorological Information Center. Dataset address: http://data.cma.cn/en/?r=data/ detail\&dataCode=SURF_CLI_CHN_MUL_DAY_CES_V3.0 (last access: 30 November 2017). The dataset can be accessed publicly, and it is free of charge for academic research. However, the dataset may not be redistributed by the data user without permission. For more information about the dataset, please contact the Climatic Data Center, data@cma.gov.cn, China Meteorological Administration, Beijing, China. The grassland database (The Qinghai province country-based grassland ecology monitoring dataset) of this study can be accessed via the following address: http://deep.qherc.org/data/category/code/2 (last access: 30 November 2017). The datasets are available to download after registration and acceptance of the data redistribution agreement. For more information and to download the dataset, please contact Liya Wang, dceepq@163.com, Data Center for Eco-Environment Protection in the Qinghai Lake Basin, Qinghai, China. The soil database (1:1000000 China soil database) can be downloaded from http: //www.issas.ac.cn/ztwz/200910/t20091015_2551708.html/ (last access: 30 November 2017). The dataset is available upon request. Contact information: Xuezheng Shi, xzshi@issas.ac.cn, Institute of Soil Science, Chinese Academy of Sciences, Nanjing, China.

\section{The Supplement related to this article is available online at https://doi.org/10.5194/bg-14-5455-2017-supplement.}

Competing interests. The authors declare that they have no conflict of interest.

Acknowledgements. We thank the editors and four anonymous reviewers for their valuable comments and suggestions on the manuscript. This study was supported by the National Natural Science Foundation of China (nos. 31672472 and 31770480), the National Key Project of Scientific and Technical Supporting Programs (2014CB138706), the Program for Changjiang Scholars and Innovative Research Team in University (IRT17R50), and the 111 project (B12002). We are grateful to the grassland station in Qinghai Province for providing data about the grassland biomass and livestock numbers in each county.

Edited by: Yakov Kuzyakov

Reviewed by: four anonymous referees 


\section{References}

Abdalla, M., Wattenbach, M., Smith, P., Ambus, P., Jones, M., and Williams, M.: Application of the DNDC model to predict emissions of $\mathrm{N}_{2} \mathrm{O}$ from Irish agriculture, Geoderma, 151, 327-337, 2009.

Araya, A., Hoogenboom, G., Luedeling, E., Hadgu, K. M., Kisekka, I., and Martorano, L. G.: Assessment of maize growth and yield using crop models under present and future climate in southwestern Ethiopia, Agr. Forest Meteorol., 214-215, 252-265, https://doi.org/10.1016/j.agrformet.2015.08.259, 2015.

Babel, W., Biermann, T., Coners, H., Falge, E., Seeber, E., Ingrisch, J., Schleuß, P.-M., Gerken, T., Leonbacher, J., Leipold, T., Willinghöfer, S., Schützenmeister, K., Shibistova, O., Becker, L., Hafner, S., Spielvogel, S., Li, X., Xu, X., Sun, Y., Zhang, L., Yang, Y., Ma, Y., Wesche, K., Graf, H.-F., Leuschner, C., Guggenberger, G., Kuzyakov, Y., Miehe, G., and Foken, T.: Pasture degradation modifies the water and carbon cycles of the Tibetan highlands, Biogeosciences, 11, 6633-6656, https://doi.org/10.5194/bg-11-6633-2014, 2014.

Bagchi, S. and Ritchie, M. E.: Introduced grazers can restrict potential soil carbon sequestration through impacts on plant community composition, Ecol. Lett., 13, 959-968, https://doi.org/10.1111/j.1461-0248.2010.01486.x, 2010.

Cao, M. and Woodward, F. I.: Dynamic responses of terrestrial ecosystem carbon cycling to global climate change, Nature, 393, 249-252, 1998.

Chen, H., Zhu, Q., Peng, C., Wu, N., Wang, Y., Fang, X., Gao, Y., Zhu, D., Yang, G., Tian, J., Kang, X., Piao, S., Ouyang, H., Xiang, W., Luo, Z., Jiang, H., Song, X., Zhang, Y., Yu, G., Zhao, X., Gong, P., Yao, T., and Wu, J.: The impacts of climate change and human activities on biogeochemical cycles on the Qinghai-Tibetan Plateau, Glob. Change Biol., 19, 2940-2955, https://doi.org/10.1111/gcb.12277, 2013.

Chen, H., Zhao, Y., Feng, H., Li, H., and Sun, B.: Assessment of climate change impacts on soil organic carbon and crop yield based on long-term fertilization applications in Loess Plateau, China, Plant Soil, 390, 401-417, https://doi.org/10.1007/s11104014-2332-1, 2015.

Conant, R. T., Paustian, K., and Elliott, E. T.: Grassland management and conversion into grassland: Effects on soil carbon, Ecol. Appl., 11, 343-355, 2001.

Davidson, E. A. and Janssens, I. A.: Temperature sensitivity of soil carbon decomposition and feedbacks to climate change, Nature, 440, 165-173, 2006.

Derner, J. D., Briske, D. D., and Boutton, T. W.: Does grazing mediate soil carbon and nitrogen accumulation beneath $\mathrm{C}-4$, perennial grasses along an environmental gradient?, Plant Soil, 191, 147156, https://doi.org/10.1023/a:1004298907778, 1997.

Di Vittorio, A. V., Chini, L. P., Bond-Lamberty, B., Mao, J., Shi, X., Truesdale, J., Craig, A., Calvin, K., Jones, A., Collins, W. D., Edmonds, J., Hurtt, G. C., Thornton, P., and Thomson, A.: From land use to land cover: restoring the afforestation signal in a coupled integrated assessment-earth system model and the implications for CMIP5 RCP simulations, Biogeosciences, 11, 6435-6450, https://doi.org/10.5194/bg-11-6435-2014, 2014.

Du, M. Y., Kawashima, S., Yonemura, S., Zhang, X. Z., and Chen, S. B.: Mutual influence between human activities and climate change in the Tibetan Plateau dur- ing recent years, Global Planet. Change, 41, 241-249, https://doi.org/10.1016/j.gloplacha.2004.01.010, 2004.

Ellis, E. C. and Ramankutty, N.: Putting people in the map: anthropogenic biomes of the world, Front. Ecol. Environ., 6, 439-447, https://doi.org/10.1890/070062, 2008.

ERSMC-a: Qinghai-Sanjiangyuan ecological monitoring integrated services platform: available at: http://www.qhepb.gov.cn/, last access: 30 November 2017.

ERSMC-b: Qinghai-Sanjiangyuan ecological monitoring integrated services platform: available at: http://deep.qherc.org/, last access: 30 November 2017.

Fan, J.-W., Shao, Q.-Q., Liu, J.-Y., Wang, J.-B., Harris, W., Chen, Z.-Q., Zhong, H.-P., Xu, X.-L., and Liu, R.-G.: Assessment of effects of climate change and grazing activity on grassland yield in the Three Rivers Headwaters Region of QinghaiTibet Plateau, China, Environ. Monit. Assess., 170, 571-584, https://doi.org/10.1007/s10661-009-1258-1, 2010.

Fortin, M. J. and Dale, M. R. T.: Spatial Analysis: A Guide for Ecologists, Cambridge University Press, New York, 2005.

$\mathrm{Fu}$, Q. and Feng, S.: Responses of terrestrial aridity to global warming, J. Geophys. Res.-Atmos., 119, 7863-7875, https://doi.org/10.1002/2014JD021608, 2014.

Gao, Q., Guo, Y., Xu, H., Ganjurjav, H., Li, Y., Wan, Y., Qin, X., Ma, X., and Liu, S.: Climate change and its impacts on vegetation distribution and net primary productivity of the alpine ecosystem in the Qinghai-Tibetan Plateau, Sci. Total Environ., 554, 34-41, https://doi.org/10.1016/j.scitotenv.2016.02.131, 2016.

Gao, Q.-Z., Wan, Y.-F., Xu, H.-M., Li, Y., Jiangcun, W.-Z., and Borjigidai, A.: Alpine grassland degradation index and its response to recent climate variability in Northern Tibet, China, Quatern. Int., 226, 143-150, https://doi.org/10.1016/j.quaint.2009.10.035, 2010.

Guevara, J. C., Stasi, C. R., and Estevez, O. R.: Effect of cattle grazing on range perennial grasses in the Mendoza plain, Argentina, J. Arid Environ., 34, 205-213, https://doi.org/10.1006/jare.1996.0102, 1996.

Hafner, S., Unteregelsbacher, S., Seeber, E., Lena, B., Xu, X., Li, X., Guggenberger, G., Miehe, G., and Kuzyakov, Y.: Effect of grazing on carbon stocks and assimilate partitioning in a Tibetan montane pasture revealed by ${ }^{13} \mathrm{CO}_{2}$ pulse labeling, Glob. Change Biol., 18, 528-538, https://doi.org/10.1111/j.13652486.2011.02557.x, 2012.

Harris, R. B.: Rangeland degradation on the QinghaiTibetan plateau: A review of the evidence of its magnitude and causes, J. Arid Environ., 74, 1-12, https://doi.org/10.1016/j.jaridenv.2009.06.014, 2010.

Hengl, T., Heuvelink, G. B. M., and Rossiter, D. G.: About regression-kriging: From equations to case studies, Comput. Geosci., 33, 1301-1315, https://doi.org/10.1016/j.cageo.2007.05.001, 2007.

Holt, J. A.: Grazing pressure and soil carbon, microbial biomass and enzyme activities in semi-arid northeastern Australia, Appl. Soil Ecol., 5, 143-149, https://doi.org/10.1016/s09291393(96)00145-x, 1997.

Hu, Z., Li, S., Guo, Q., Niu, S., He, N., Li, L., and Yu, G.: A synthesis of the effect of grazing exclusion on carbon dynamics in grasslands in China, Glob. Change Biol., 22, 1385-1393, https://doi.org/10.1111/gcb.13133, 2016. 
Ingrisch, J., Biermann, T., Seeber, E., Leipold, T., Li, M., Ma, Y., $\mathrm{Xu}, \mathrm{X}$., Miehe, G., Guggenberger, G., Foken, T., and Kuzyakov, Y.: Carbon pools and fluxes in a Tibetan alpine Kobresia pygmaea pasture partitioned by coupled eddy-covariance measurements and ${ }^{13} \mathrm{CO}_{2}$ pulse labeling, Sci. Total Environ., 505, 12131224, https://doi.org/10.1016/j.scitotenv.2014.10.082, 2015.

IPCC: Climate Change 2013: The Physical Science Basis. Contribution of Working Group I to the Fifth Assessment Report of the Intergovernmental Panel on Climate Change, Cambridge University Press, Cambridge, United Kingdom and New York, NY, USA, 1535 pp., 2013.

Jobbagy, E. G. and Jackson, R. B.: The vertical distribution of soil organic carbon and its relation to climate and vegetation, Ecol. Appl., 10, 423-436, https://doi.org/10.2307/2641104, 2000.

Kariyapperuma, K. A., Wagner-Riddle, C., Furon, A. C., and Li, C.: Assessing Spring Thaw Nitrous Oxide Fluxes Simulated by the DNDC Model for Agricultural Soils, Soil Sci. Soc. Am. J., 75, 678-690, https://doi.org/10.2136/sssaj2010.0264, 2011.

Kirschbaum, M. U. F.: The Temperature-Dependence Of Soil Organic-Matter Decomposition, And The Effect Of Global Warming On Soil Organic-C Storage, Soil Biol. Biochem., 27, 753-760, https://doi.org/10.1016/0038-0717(94)00242-s, 1995.

Klein, J. A., Harte, J., and Zhao, X.-Q.: Experimental warming, not grazing, decreases rangeland quality on the Tibetan Plateau, Ecol. Appl., 17, 541-557, 2007.

Koerner, S. E. and Collins, S. L.: Interactive effects of grazing, drought, and fire on grassland plant communities in North America and South Africa, Ecology, 95, 98-109, https://doi.org/10.1890/13-0526.1, 2014.

Kvenvolden, K. A.: Gas hydrates-geological perspective and global change, Rev. Geophys., 31, 173-187, https://doi.org/10.1029/93RG00268, 1993.

Lavado, R. S., Sierra, J. O., and Hashimoto, P. N.: Impact of grazing on soil nutrients in a Pampean grassland, J. Range Manage., 49, 452-457, https://doi.org/10.2307/4002929, 1996.

Lehnert, L. W., Wesche, K., Trachte, K., Reudenbach, C., and Bendix, J.: Climate variability rather than overstocking causes recent large scale cover changes of Tibetan pastures, Scientific Reports, 6, 24367, https://doi.org/10.1038/srep24367, 2016.

Li, C.: The DNDC Model, in: Evaluation of Soil Organic Matter Models: Using Existing Long-Term Datasets, edited by: Powlson, D. S., Smith, P., and Smith, J. U., Springer Berlin Heidelberg, Berlin, Heidelberg, 263-267, 1996.

Li, C.: User's Guide for the DNDC Model: available at: http: //www.dndc.sr.unh.edu/model/GuideDNDC95.pdf (last access: 30 November 2017), 2012.

Li, C. S., Frolking, S., and Frolking, T. A.: A Model Of NitrousOxide Evolution From Soil Driven By Rainfall Events: 1. Model Structure And Sensitivity, J. Geophys. Res.-Atmos., 97, 97599776, 1992.

Li, C. S., Narayanan, V., and Harriss, R. C.: Model estimates of nitrous oxide emissions from agricultural lands in the United States, Global Biogeochem. Cy., 10, 297-306, https://doi.org/10.1029/96gb00470, 1996.

Li, C. S., Farahbakhshazad, N., Jaynes, D. B., Dinnes, D. L., Salas, W., and McLaughlin, D.: Modeling nitrate leaching with a biogeochemical model modified based on observations in a row-crop field in Iowa, Ecol. Model., 196, 116-130, https://doi.org/10.1016/j.ecolmodel.2006.02.007, 2006.
Li, H., Wang, L., Li, J., Gao, M., Zhang, J., Zhang, J., Qiu, J., Deng, J., Li, C., and Frolking, S.: The development of China-DNDC and review of its applications for sustaining Chinese agriculture, Ecol. Model., 348, 1-13, https://doi.org/10.1016/j.ecolmodel.2017.01.003, 2017.

Li, L., Yang, S., Wang, Z., Zhu, X., and Tang, H.: Evidence of warming and wetting climate over the Qinghai-Tibet Plateau, Arct. Antarct. Alp. Res., 42, 449-457, 2010.

Li, R. H., Li, X. B., Li, G. Q., and Wen, W. Y.: Simulation of soil nitrogen storage of the typical steppe with the DNDC model: A case study in Inner Mongolia, China, Ecol. Indic., 41, 155-164, https://doi.org/10.1016/j.ecolind.2014.01.043, 2014.

Li, S., Lu, S., Gao, Y., and Ao, Y.: The change of climate and terrestrial carbon cycle over Tibetan Plateau in CMIP5 models, Int. J. Climatol., 35, 4359-4369, https://doi.org/10.1002/joc.4293, 2015.

Li, W., Huang, H. Z., Zhang, Z. N., and Wu, G. L.: Effects of grazing on the soil properties and $\mathrm{C}$ and $\mathrm{N}$ storage in relation to biomass allocation in an alpine meadow, J. Soil Sci. Plant Nut., 11, 27-39, https://doi.org/10.4067/s0718-95162011000400003, 2011.

Li, X. L., Gao, J., Brierley, G., Qiao, Y. M., Zhang, J., and Yang, Y. W.: Rangeland Degradation On The Qinghai-Tibet Plateau: Implications For Rehabilitation, Land Degrad. Dev., 24, 72-80, https://doi.org/10.1002/ldr.1108, 2013.

Li, Y., Luo, T., and Lu, Q.: Plant height as a simple predictor of the root to shoot ratio: Evidence from alpine grasslands on the Tibetan Plateau, J. Veg. Sci., 19, 245-252, https://doi.org/10.3170/2007-8-18365, 2008.

Li, Y., Dong, S., Wen, L., Wang, X., and Wu, Y.: Assessing the soil quality of alpine grasslands in the Qinghai-Tibetan Plateau using a modified soil quality index, Environ. Monit. Assess., 185, 8011-8022, https://doi.org/10.1007/s10661-013-3151-1, 2013.

Li, Z., Huffman, T., McConkey, B., and Townley-Smith, L.: Monitoring and modeling spatial and temporal patterns of grassland dynamics using time-series MODIS NDVI with climate and stocking data, Remote Sens. Environ., 138, 232-244, https://doi.org/10.1016/j.rse.2013.07.020, 2013.

Li, R. H., Li, X. B., Li, G. Q., and Wen, W. Y.: Simulation of soil nitrogen storage of the typical steppe with the DNDC model: A case study in Inner Mongolia, China, Ecol. Indic., 41, 155-164, https://doi.org/10.1016/j.ecolind.2014.01.043, 2014.

Liu, S., Schleuss, P.-M., and Kuzyakov, Y.: Carbon and Nitrogen Losses from Soil Depend on Degradation of Tibetan Kobresia Pastures, Land Degrad. Dev., 28, 1253-1262, https://doi.org/10.1002/ldr.2522, 2017.

Liu, Y., Yu, Z., Chen, J., Zhang, F., Doluschitz, R., and Axmacher, J. C.: Changes of soil organic carbon in an intensively cultivated agricultural region: A denitrification-decomposition (DNDC) modelling approach, Sci. Total Environ., 372, 203-214, 2006.

López-Mársico, L., Altesor, A., Oyarzabal, M., Baldassini, P., and Paruelo, J. M.: Grazing increases below-ground biomass and net primary production in a temperate grassland, Plant Soil, 392, 155-162, https://doi.org/10.1007/s11104-015-2452-2, 2015.

Luo, C., Xu, G., Chao, Z., Wang, S., Lin, X., Hu, Y., Zhang, Z., Duan, J., Chang, X., Su, A., Li, Y., Zhao, X., Du, M., Tang, Y., and Kimball, B.: Effect of warming and grazing on litter mass loss and temperature sensitivity of litter and dung mass 
loss on the Tibetan plateau, Glob. Change Biol., 16, 1606-1617, https://doi.org/10.1111/j.1365-2486.2009.02026.x, 2010.

Maussion, F., Scherer, D., Mölg, T., Collier, E., Curio, J., and Finkelnburg, R.: Precipitation Seasonality and Variability over the Tibetan Plateau as Resolved by the High Asia Reanalysis, J. Climate, 27, 1910-1927, https://doi.org/10.1175/jcli-d-1300282.1, 2014.

McIntire, E. J. B. and Hik, D. S.: Influences of chronic and current season grazing by collared pikas on above-ground biomass and species richness in subarctic alpine meadows, Oecologia, 145, 288-297, https://doi.org/10.1007/s00442-005-0127-z, 2005.

Mebius, L. J.: A rapid method for the determination of organic carbon in soil, Anal. Chim. Acta, 22, 120-124, https://doi.org/10.1016/S0003-2670(00)88254-9, 1960.

Meinshausen, M., Smith, S. J., Calvin, K., Daniel, J. S., Kainuma, M. L. T., Lamarque, J. F., Matsumoto, K., Montzka, S. A., Raper, S. C. B., Riahi, K., Thomson, A., Velders, G. J. M., and van Vuuren, D. P. P.: The RCP greenhouse gas concentrations and their extensions from 1765 to 2300, Climatic Change, 109, 213-241, https://doi.org/10.1007/s10584-011-0156-z, 2011.

Miehe, G., Schleuss, P.-M., Seeber, E., Babel, W., Biermann, T., Braendle, M., Chen, F., Coners, H., Foken, T., Gerken, T., Graf, H.-F., Guggenberger, G., Hafner, S., Holzapfel, M., Ingrisch, J., Kuzyakov, Y., Lai, Z., Lehnert, L., Leuschner, C., Liu, J., Liu, S., Ma, Y., Miehe, S., Mosbrugger, V., Noltie, H. J., Opgenoorth, L., Schmidt, J., Spielvogel, S., Unteregelsbacher, S., Wang, Y., Willinghofer, S., Xu, X., Yang, Y., Zhang, S., and Wesche, K.: The Kobresia pygmaea Ecosystem Of The Tibetan Highlands: Origin, Functioning And Degradation Of The World's Largest Pastoral Alpine Ecosystem, bioRxiv, https://doi.org/10.1101/135558, 2017.

Miehle, P.: Quantifying uncertainty from large-scale model predictions of forest carbon dynamics, Glob. Change Biol., 12, 14211434, https://doi.org/10.1111/j.1365-2486.2006.01176.x, 2006.

Milchunas, D. G. and Lauenroth, W. K.: Quantitative Effects of Grazing on Vegetation and Soils over a Global Range of Environments, Ecol. Monogr., 63, 327-366, https://doi.org/10.2307/2937150, 1993.

Moss, R. H., Edmonds, J. A., Hibbard, K. A., Manning, M. R., Rose, S. K., van Vuuren, D. P., Carter, T. R., Emori, S., Kainuma, M., Kram, T., Meehl, G. A., Mitchell, J. F. B., Nakicenovic, N., Riahi, K., Smith, S. J., Stouffer, R. J., Thomson, A. M., Weyant, J. P., and Wilbanks, T. J.: The next generation of scenarios for climate change research and assessment, Nature, 463, 747-756, 2010.

Naeth, M. A., Bailey, A. W., Pluth, D. J., Chanasyk, D. S., and Hardin, R. T.: Grazing Impacts On Litter And Soil Organic-Matter In Mixed Prairie And Fescue Grassland Ecosystems Of Alberta, J. Range Manage., 44, 7-12, https://doi.org/10.2307/4002629, 1991.

Pei, S., Fu, H., and Wan, C.: Changes in soil properties and vegetation following exclosure and grazing in degraded Alxa desert steppe of Inner Mongolia, China, Agr. Ecosyst. Environ., 124, 33-39, https://doi.org/10.1016/j.agee.2007.08.008, 2008.

Pei, Z.-Y., Ouyang, H., Zhou, C.-P., and Xu, X.-L.: Carbon Balance in an Alpine Steppe in the Qinghai-Tibet Plateau, J. Integr. Plant Biol., 51, 521-526, https://doi.org/10.1111/j.17447909.2009.00813.x, 2009.

Piao, S., Tan, K., Nan, H., Ciais, P., Fang, J., Wang, T., Vuichard, N., and Zhu, B.: Impacts of climate and $\mathrm{CO}_{2}$ changes on the veg- etation growth and carbon balance of Qinghai-Tibetan grasslands over the past five decades, Global Planet. Change, 98-99, 73-80, https://doi.org/10.1016/j.gloplacha.2012.08.009, 2012.

Qiao, N., Xu, X., Cao, G., Ouyang, H., and Kuzyakov, Y.: Land use change decreases soil carbon stocks in Tibetan grasslands, Plant Soil, 395, 231-241, https://doi.org/10.1007/s11104-015-2556-8, 2015.

Qin, Y., Yi, S., Ren, S., Li, N., and Chen, J.: Responses of typical grasslands in a semi-arid basin on the Qinghai-Tibetan Plateau to climate change and disturbances, Environ. Earth Sci., 71, 14211431, https://doi.org/10.1007/s12665-013-2547-0, 2014.

QPBS: Qinghai Statistical Yearbook 2015, China Statistics Press, Beijing, 2005.

QPBS: Qinghai Statistical Yearbook 2015, China Statistics Press, Beijing, 2015.

Riedo, M., Gyalistras, D., and Fuhrer, J.: Net primary production and carbon stocks in differently managed grasslands: simulation of site-specific sensitivity to an increase in atmospheric $\mathrm{CO} 2$ and to climate change, Ecol. Model., 134, 207-227, https://doi.org/10.1016/s0304-3800(00)00356-2, 2000.

Schuman, G. E., Reeder, J. D., Manley, J. T., Hart, R. H., and Manley, W. A.: Impact of Grazing Management on the Carbon and Nitrogen Balance of a Mixed-Grass Rangeland, Ecol. Appl., 9, 65-71, 1999.

Schuur, E. A. G.: Productivity and global climate revisited: The sensitivity of tropical forest growth to precipitation, Ecology, 84, 1165-1170, https://doi.org/10.1890/00129658(2003)084[1165:PAGCRT]2.0.CO;2, 2003.

Shen, M., Tang, Y., Chen, J., Zhu, X., and Zheng, Y.: Influences of temperature and precipitation before the growing season on spring phenology in grasslands of the central and eastern Qinghai-Tibetan Plateau, Agr. Forest Meteorol., 151, 17111722, https://doi.org/10.1016/j.agrformet.2011.07.003, 2011.

Shi, X. Z., Yu, D. S., Warner, E. D., Pan, X. Z., Petersen, G. W., Gong, Z. G., and Weindorf, D. C.: Soil database of $1: 1000000$ digital soil survey and reference system of the Chinese Genetic Soil Classification System, Soil Survey Horizons, 45, 129-136, 2004.

Tan, K., Ciais, P., Piao, S., Wu, X., Tang, Y., Vuichard, N., Liang, S., and Fang, J.: Application of the ORCHIDEE global vegetation model to evaluate biomass and soil carbon stocks of Qinghai-Tibetan grasslands, Global Biogeochem. Cy., 24, GB1013, https://doi.org/10.1029/2009gb003530, 2010.

Tanentzap, A. J. and Coomes, D. A.: Carbon storage in terrestrial ecosystems: do browsing and grazing herbivores matter?, Biol. Rev., 87, 72-94, https://doi.org/10.1111/j.1469185X.2011.00185.x, 2012.

van Vuuren, D., Edmonds, J., Kainuma, M., Riahi, K., Thomson, A., Hibbard, K., Hurtt, G., Kram, T., Krey, V., Lamarque, J.-F., Masui, T., Meinshausen, M., Nakicenovic, N., Smith, S., and Rose, S.: The representative concentration pathways: an overview, Climatic Change, 109, 5-31, https://doi.org/10.1007/s10584-0110148-z, 2011.

Veen, G. F., Geuverink, E., and Olff, H.: Large grazers modify effects of aboveground-belowground interactions on smallscale plant community composition, Oecologia, 168, 511-518, https://doi.org/10.1007/s00442-011-2093-y, 2012.

Wang, G., Li, Y., Wang, Y., and Wu, Q.: Effects of permafrost thawing on vegetation and soil carbon pool losses on 
the Qinghai-Tibet Plateau, China, Geoderma, 143, 143-152, https://doi.org/10.1016/j.geoderma.2007.10.023, 2008.

Wang, G. X., Qian, J., Cheng, G. D., and Lai, Y. M.: Soil organic carbon pool of grassland soils on the Qinghai-Tibetan Plateau and its global implication, Sci. Total Environ., 291, 207-217, 2002.

Wienhold, B. J., Hendrickson, J. R., and Karn, J. F.: Pasture management influences on soil properties in the Northern Great Plains, J. Soil Water Conserv., 56, 27-31, 2001.

Willmott, C. J.: Some Comments on the Evaluation of Model Performance, B. Am. Meteorol. Soc., 63, 1309-1313, https://doi.org/10.1175/15200477(1982)063<1309:SCOTEO>2.0.CO;2, 1982.

Wu, G.-L., Du, G.-Z., Liu, Z.-H., and Thirgood, S.: Effect of fencing and grazing on a Kobresia-dominated meadow in the Qinghai-Tibetan Plateau, Plant Soil, 319, 115-126, https://doi.org/10.1007/s11104-008-9854-3, 2009.

Xu, G., Hu, Y., Wang, S., Zhang, Z., Chang, X., Duan, J., Luo, C., Chao, Z., Su, A., Lin, Q., Li, Y., and Du, M.: Effects of litter quality and climate change along an elevation gradient on litter mass loss in an alpine meadow ecosystem on the Tibetan plateau, Plant Ecol., 209, 257-268, https://doi.org/10.1007/s11258-0099714-0, 2010.

$\mathrm{Xu}, \mathrm{R}$. , Wang, M., and Wang, Y.: Using a modified DNDC model to estimate $\mathrm{N}_{2} \mathrm{O}$ fluxes from semi-arid grassland in China, Soil Biol. Biochem., 35, 615-620, https://doi.org/10.1016/s00380717(03)00009-9, 2003.

Xu, X., Sherry, R. A., Niu, S., Zhou, J., and Luo, Y.: Long-term experimental warming decreased labile soil organic carbon in a tallgrass prairie, Plant Soil, 361, 307-315, https://doi.org/10.1007/s11104-012-1265-9, 2012.

Xu, Y., Xu, C. H., Gao, X. J., and Luo, Y.: Projected changes in temperature and precipitation extremes over the Yangtze River Basin of China in the 21st century, Quatern. Int., 208, 44-52, https://doi.org/10.1016/j.quaint.2008.12.020, 2009.

Yan, L., Zhou, G., and Zhang, F.: Effects of Different Grazing Intensities on Grassland Production in China: A Meta-Analysis, Plos One, 8, e81466, https://doi.org/10.1371/journal.pone.0081466, 2013.

Yan, L., Zhou, G. S., Wang, Y. H., Hu, T. Y., and Sui, X. H.: The spatial and temporal dynamics of carbon budget in the alpine grasslands on the Qinghai-Tibetan Plateau using the Terrestrial Ecosystem Model, J. Clean. Prod., 107, 195-201, https://doi.org/10.1016/j.jclepro.2015.04.140, 2015.

Yang, Y., Fang, J., Tang, Y., Ji, C., Zheng, C., He, J., and Zhu, B.: Storage, patterns and controls of soil organic carbon in the Tibetan grasslands, Glob. Change Biol., 14, 1592-1599, https://doi.org/10.1111/j.1365-2486.2008.01591.x, 2008.

Yu, D.-S., Shi, X.-Z., Wang, H.-J., Sun, W.-X., Warner, E. D., and Liu, Q.-H.: National Scale Analysis of Soil Organic Carbon Storage in China Based on Chinese Soil Taxonomy, Pedosphere, 17, 11-18, 2007a.
Yu, D. S., Shi, X. Z., Wang, H. J., Sun, W. X., Chen, J. M., Liu, Q. H., and Zhao, Y. C.: Regional patterns of soil organic carbon stocks in China, J. Environ. Manage., 85, 680-689, 2007 b.

Zeng, C., Wu, J., and Zhang, X.: Effects of Grazing on Abovevs. Below-Ground Biomass Allocation of Alpine Grasslands on the Northern Tibetan Plateau, Plos One, 10, e0135173, https://doi.org/10.1371/journal.pone.0135173, 2015.

Zhang, B.: On the Livestock Development of Qinghai Province during the Time of Republic of China (1912-1949), Ancient and Modern Agriculture, 3, 91-100, 2011.

Zhang, R., Li, Z., Yuan, Y., Li, Z., and Yin, F.: Analyses on the Changes of Grazing Capacity in the ThreeRiver Headwaters Region of China under Various Climate Change Scenarios, Adv. Meteorol., 2013, e0135173, https://doi.org/10.1155/2013/951261, 2013.

Zhang, W., Liu, C., Zheng, X., Zhou, Z., Cui, F., Zhu, B., Haas, E., Klatt, S., Butterbach-Bahl, K., and Kiese, R.: Comparison of the DNDC, LandscapeDNDC and IAP-N-GAS models for simulating nitrous oxide and nitric oxide emissions from the winter wheat-summer maize rotation system, Agr. Syst., 140, 1-10, 2015.

Zhang, Y., Min, Q., Zhao, G., Jiao, W., Liu, W., and Bijaya, G. C. D.: Can Clean Energy Policy Improve the Quality of Alpine Grassland Ecosystem? A Scenario Analysis to Influence the Energy Changes in the Three-River Headwater Region, China, Sustainability, 8, su8030231, https://doi.org/10.3390/su8030231, 2016.

Zhang, Y. and Niu, H.: The development of the DNDC plant growth sub-model and the application of DNDC in agriculture: A review, Agr. Ecosyst. Environ., 230, 271-282, https://doi.org/10.1016/j.agee.2016.06.017, 2016.

Zhao, Z., Sha, Z., Liu, Y., Wu, S., Zhang, H., Li, C., Zhao, Q., and Cao, L.: Modeling the impacts of alternative fertilization methods on nitrogen loading in rice production in Shanghai, Sci. Total Environ., 566-567, 1595-1603, https://doi.org/10.1016/j.scitotenv.2016.06.055, 2016.

Zhou, D., Fan, G., Huang, R., Fang, Z., Liu, Y., and Li, H.: Interannual variability of the normalized difference vegetation index on the Tibetan plateau and its relationship with climate change, Adv. Atmos. Sci., 24, 474-484, https://doi.org/10.1007/s00376007-0474-2, 2007.

Zhu, X. J., Yu, G. R., Wang, Q. F., Gao, Y. N., He, H. L., Zheng, H., Chen, Z., Shi, P. L., Zhao, L., Li, Y. N., Wang, Y. F., Zhang, Y. P., Yan, J. H., Wang, H. M., Zhao, F. H., and Zhang, J. H.: Approaches of climate factors affecting the spatial variation of annual gross primary productivity among terrestrial ecosystems in China, Ecol. Indic., 62, 174-181, https://doi.org/10.1016/j.ecolind.2015.11.028, 2016. 